\title{
Seasonal changes in snow surface roughness characteristics at Summit, Greenland: implications for snow and firn ventilation
}

\author{
Mary R. ALBERT, ${ }^{1}$ Robert L. HAWLEY ${ }^{2}$ \\ ${ }^{1}$ U.S. Army Cold Regions Research and Engineering Laboratory, 72 Lyme Road, Hanover, NH 03755-1290, U.S.A. \\ E-mail:malbert@hanover-crrel.army.mil \\ ${ }^{2}$ Geophysics Program, Department of Earth and Space Sciences, Box 351650, University of Washington, Seattle,WA 98195-1650, U.S.A.
}

\begin{abstract}
Air-snow transfer processes impact both ice-core interpretation and exchange affecting atmospheric chemistry. An understanding of seasonal differences in the character of the surface snow will facilitate evaluation of possible preferential seasonal exchange of reactive chemical species. Both diffusive processes and advective (ventilation) processes can serve to alter the physical, chemical and isotopic character of snow and firn. In this paper, we examine measurements of surface roughness over the course of a year at Summit, Greenland, and the implications for snow and firn ventilation. At Summit, during the winter-over experiment, summer and fall sastrugi amplitudes were approximately $5 \mathrm{~cm}$ and had smoothly curved profiles. The average amplitudes experienced mild increases in January, but by the end of February through March the amplitude increased to approximately $20 \mathrm{~cm}$, and the profiles exhibited more abrupt geometries. Calculations are performed to show the potential impact of the changing roughness on interstitial ventilation rates in the snow, assuming that the permeability profile does not change in time. Under high winds, ventilation velocities in the near-surface snow can be up to $3 \mathrm{~cm} \mathrm{~s}^{-1}$ in the winter, compared to $1 \mathrm{~cm} \mathrm{~s}^{-1}$ in the summer. The frequency of $12 \mathrm{~m} \mathrm{~s}^{-1}$ winds in the summer, however, is less than in the winter. Under low-wind conditions, the summer roughness causes ventilation rates that are comparable to diffusion rates. However, in winter even $5 \mathrm{~m} \mathrm{~s}^{-1}$ wind conditions can cause the interstitial airflow due to ventilation to exceed the diffusion rates.
\end{abstract}

\section{INTRODUGTION}

Processes of air-snow transfer affect the deposition and postdepositional change of atmospheric chemical species and the record of those species within the snow, firn and, eventually, ice cores. An understanding of seasonal differences in the character of the snow and their impact on surface processes may facilitate evaluation of possible preferential seasonal signals in ice-core records. While diffusion across the air-snow interface is ubiquitous, advection of water vapor and gaseous chemical species within the snow can also occur by ventilation, the wind-induced interstitial airflow caused by "form drag" pressure variations across snow roughness features such as sastrugi (e.g. Colbeck, 1989; Albert, 1996; Waddington and others, 1996). Ventilation of the snow can influence the temperature and chemical composition of the snow and firn (e.g. Albert, 1993; Cunningham and Waddington, 1993; McConnell and others, 1998). Winds across greater surface roughness provide the forcing for increased subsurface ventilation, but small surface features such as sastrugi move in time, and their size and even existence can experience seasonal differences.

In pit studies at South Pole, Gow (1965) and Gow and Rowland (1965) found that the bulk of the year's accumulation was deposited as dunes during the winter; the dunes were subsequently eroded into sastrugi by the winds, and became more leveled during the summer by a process of sublimation-deflation, with the result that the winter's true roughness is rarely if ever recorded in the stratigraphy. They concluded that the stratigraphy at the South Pole could be said to reflect conditions at the end of summer rather than at the end of winter. In studies at Plateau station, Antarctica, Weller (1969) found that differences in the amount of radiation absorbed by the various faces of sastrugi were important in the observed preferential erosion, which tended to level the surface. From pit studies and variability of snowstake data at Byrd Station, Antarctica, Benson (1971) confirmed the concept of the summer erosion of sastrugi, and he found an annual variation in sastrugi development, with the maximum irregularity late in winter and the minimum irregularity in summer. In this paper we examine measurements of surface roughness that were made on the centimeter-to-meter scale over the course of the 1998 winter at Summit, Greenland. Calculations of snow and firn ventilation under the several limiting conditions of surface roughness and wind speed will be presented.

\section{THE MEASUREMENTS}

By leveling a thin blade several meters long into the surface snow, profiles of the surface relief were measured at several points in time. Figure 1 depicts a schematic of the measurement device. The roughness was characterized by measuring the height change between the surface of the snow and a horizontal datum at $10 \mathrm{~cm}$ increments along the $2.5 \mathrm{~m}$ blade, or more frequent increments where changes in slope were steep. A bubble indicator on the top of the blade served as the indicator for levelling the blade. These measurements were made on surface features that were judged to be characteristic of the surrounding roughness, at a site away from all buildings and 
Air

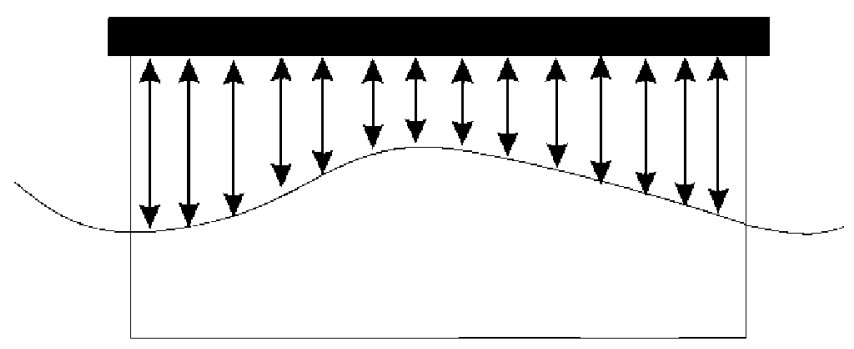

\section{Snow}

Fig. 1. Schematic of the snow blade.

other possible obstructions. In addition to these measurements, peak-to-peak measurements of roughness features in the predominant wind direction were measured for 10 sastrugi using a reeled tape measure. It should be noted that the sastrugi at Summit do not appear as long uniform wave fronts in the snow, but rather as distributed bumps across an otherwise very flat landscape. Nevertheless, it is useful for modeling purposes to have an estimate of a characteristic amplitude and wavelength.

\section{RESULTS}

Figure 2 depicts the results of the snow roughness blade measurements. Between September and January, the field personnel could not find roughness that they considered to be significant; the roughness during that time period was less than the $5 \mathrm{~cm}$ heights observed in September and January. Summer and fall sastrugi amplitudes ranged between 3 and

June 28

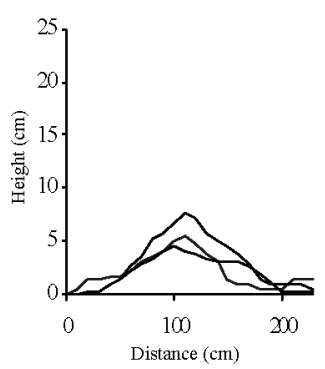

February 27

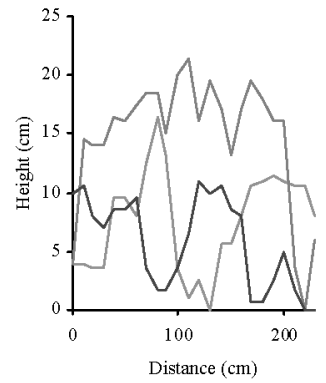

September 25
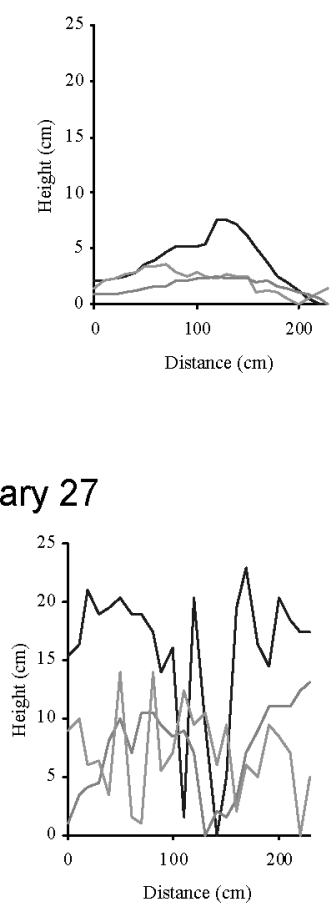

$8 \mathrm{~cm}$ and had smoothly curved profiles. The average amplitudes experienced mild increases in January, but by the end of February through March the amplitudes increased to approximately $20 \mathrm{~cm}$, and the profiles exhibited more abrupt geometries. The roughness amplitudes over time are plotted in Figure $3 \mathrm{a}$, where again it is evident that the roughness was significantly more pronounced in the late winter at Summit. The peak-to-peak distances between roughness elements, or roughness wavelengths, are shown in Figure 4. The wavelengths of the surface roughness elements are variable, and fall between 5 and $20 \mathrm{~m}$ for most of the measurements. It is evident that, although the amplitude of the snow roughness elements is seasonally dependent, the wavelength of the snow surface roughness at Summit does not show dramatic differences between seasons.

Meteorological and snowfall conditions have an impact on surface roughness. Most polar sites experience occasional or frequent strong winds that cause blowing snow and snow redistribution both during and between snowfall events, and it is often difficult for an observer to identify whether suspended snow is due to snowfall or is wind-driven blowing snow. The timing of the new snowfall may be inferred from data from the ultrasonic snow-depth sensor. This sensor detects the distance between the sensor (suspended at a fixed location above the snow) and the snow surface. This distance can be affected by blowing-snow events and by snow accumulation. In Figure 5 the increase in snow depth as determined from an ultrasonic snow-depth sensor is shown; the readings obviously affected by blowing snow have been removed from the data. The light thin line is the measured data using the acoustic snow-depth sensor, the solid line is our visual interpretation of the mean snow depth from the graph of the acoustic measurements, the dotted spikes represent the accumulation inferred from the mean snow-depth increase, and the small diamonds are the snow roughness amplitudes from Figure 3, included here for comparison to the other data. Some of the snow surface chemistry measurements have con-
January 14

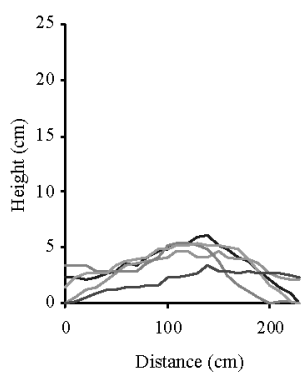

January 26

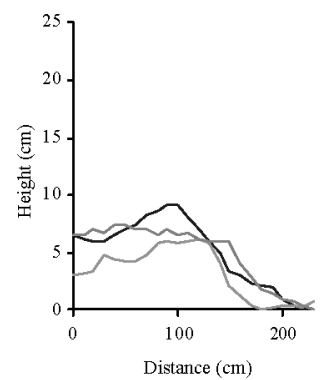

March 25
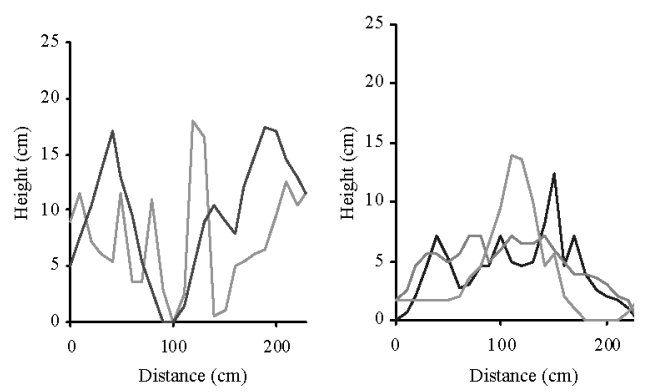

Fig. 2. Measured roughness profiles. 


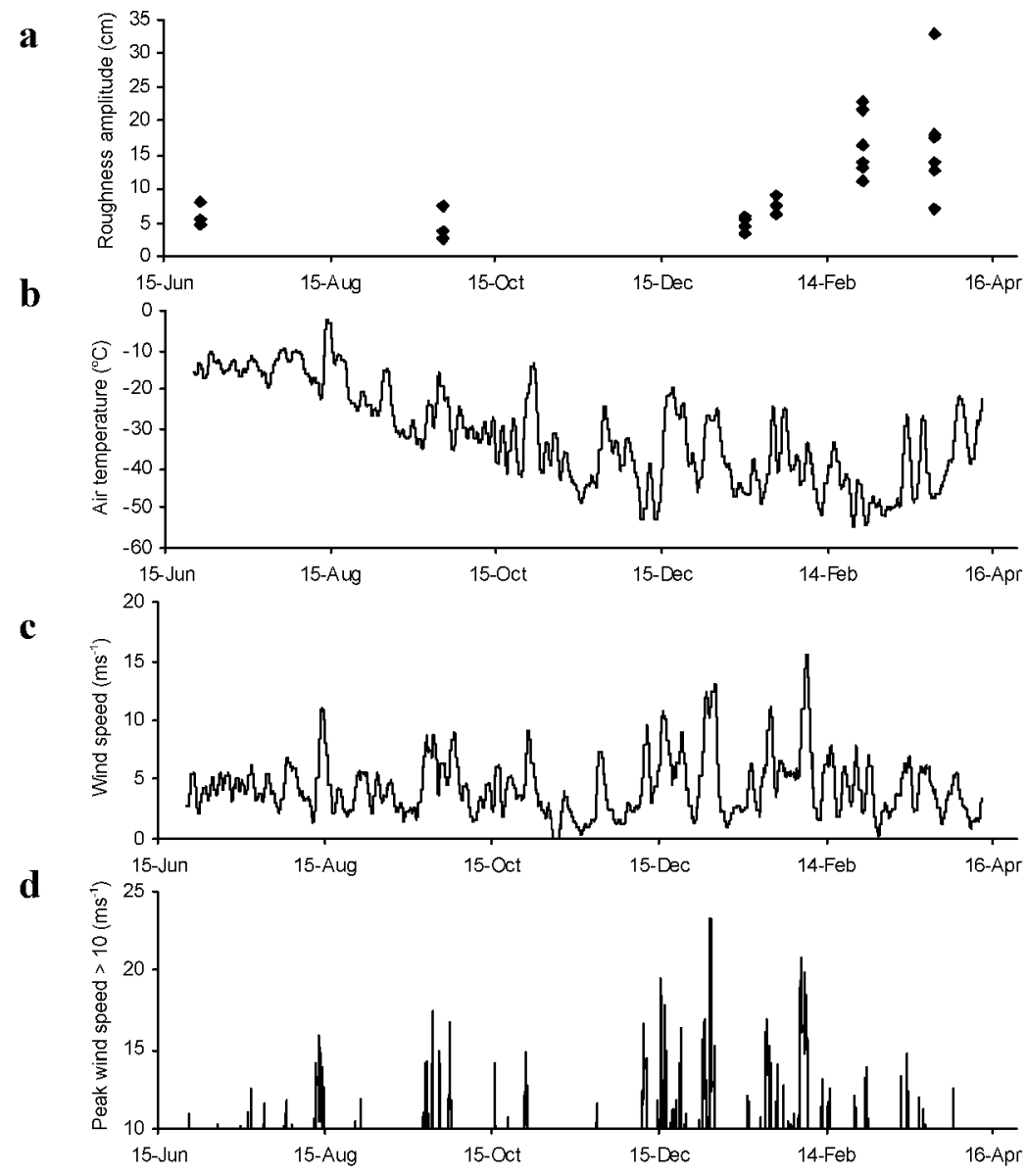

Fig. 3. Snow roughness amplitude (a), air temperature (b), mean wind speed (c), and peak wind speeds $>10 \mathrm{~ms}^{-1}(d)$ at Summit during the winter-over experiment.

firmed the snowfall events (personal communication from A. Stanzick, 2000). From this graph it is evident that snowfall does occur throughout the year at Summit, although snowfall alone does not correlate to surface roughness.

In Figure 3, roughness amplitudes are plotted along with air temperature, mean wind speed, and wind speeds $>10 \mathrm{~ms}^{-1}$. Evidently the strong winds of December are accompanied by relatively warm air temperatures $\left(-20^{\circ} \mathrm{C}\right)$, while the strong winds of January and February occur when air temperatures are colder $\left(-30^{\circ} \mathrm{C}\right.$ and colder $)$. While more detailed studies of surface roughness formation are needed for a thorough explanation, it is evident from this figure that sustained high winds and very cold temperatures may act in concert to promote the formation of increased surface roughness.

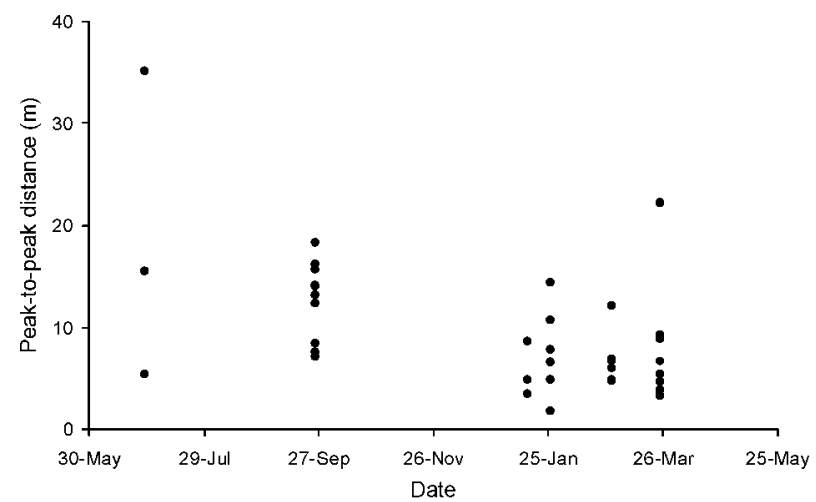

Fig. 4. Snow roughness wavelength from peak-to-peak measurements during the winter-over experiments.

\section{IMPLICATIONS FOR SNOWAND FIRN VENTILATION}

Wind and surface roughness act in concert to induce pressure variations across the surface. These pressure variations drive ventilation, or interstitial airflow through snow. The data on surface roughness show that the wavelengths of the surface roughness range between 5 and $20 \mathrm{~m}$ year-round, while the amplitudes of the roughness are $<8 \mathrm{~cm}$ for much of the year except in late winter to early spring, when they increase to $25 \mathrm{~cm}$ or less. Both the increased size of the snow roughness elements and the increased wind in winter imply that snow and firn ventilation is likely to be more intense in the late winter and early spring than in late summer or fall.

Calculated airflow patterns for late winter and late summer will be investigated using the two-dimensional finiteelement ventilation model that is described in detail in Albert (1996). Surface pressure variations are dependent

Table 1. Parameters for the model runs

\begin{tabular}{lcccc}
\hline & \multicolumn{2}{c}{ Snow roughness } & & \\
& Amplitude & Wavelength & & \\
& $\mathrm{m}$ & $\mathrm{m}$ & $\mathrm{m} \mathrm{s}^{-1}$ & $\mathrm{~N} \mathrm{~m}^{-2}$ \\
& & & & \\
\hline & 0.08 & 5 & 12 & 8.9 \\
Case 1 (summer) & 0.25 & 20 & 5 & 1.2 \\
Case 2 (winter) & 0.08 & 20 & 5 & 0.39 \\
Case 3 (summer) & 0.25 & 5 & 12 & 28.0 \\
Case 4 (winter) & & & & \\
\hline
\end{tabular}




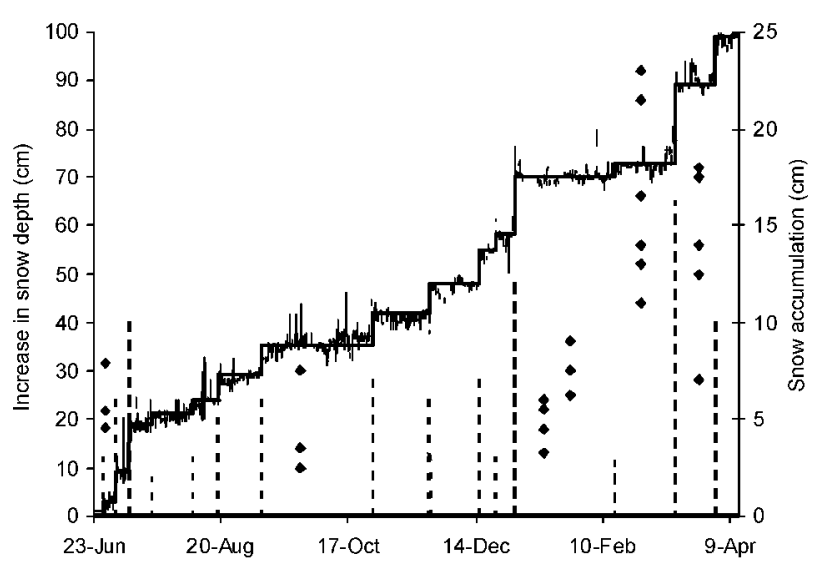

Fig. 5. Snow depth, accumulation and sastrugi amplitudes during the winter-over experiment. The light thin line is the measured acoustic snow-depth data; the solid line is our visual interpretation of the mean snow depth from the graph of the acoustic measurements; the dotted spikes represent the accumulation inferred from the mean snow-depth increase; and the small diamonds are the amplitudes of the snow roughness.

upon the wind speed and also upon the roughness geometry. For these calculations we employ surface roughness pressure variations measured by Vanoni and Hwang (1967) for water flow over sinusoidal dunes; these data were scaled by Colbeck (1989) for airflow over a sinusoidal snow surface. From these studies, the amplitude of the maximum pressure difference induced by steady flow over a sinusoidal wavy surface is given in Equation (1):

$$
p_{0}=C \rho_{\mathrm{air}} U_{10}^{2} \frac{h}{\lambda}
$$

where $p_{0}$ is the amplitude of the pressure when the pressure forcing follows a sinusoidal profile spatially, $\rho_{\text {air }}$ is the density of air, $U_{10}$ is the wind speed at $10 \mathrm{~m}$ height, $h$ is the amplitude of the surface roughness, $\lambda$ is the wavelength of the surface roughness, and the constant of proportionality, $C$, was determined (Colbeck, 1989) to be approximately 3. We will now use this idealized pressure amplitude to estimate the seasonal pressure variation across the surface roughness. For the calculations we will select $5 \mathrm{~m} \mathrm{~s}^{-1}$ as a typical low wind speed, and $12 \mathrm{~m} \mathrm{~s}^{-1}$ as a high wind speed. From the measured roughness lengths, $5 \mathrm{~m}$ would be representative of a short length, and $20 \mathrm{~m}$ would represent a long wavelength. We take $8 \mathrm{~cm}$ to represent summer conditions, and $25 \mathrm{~cm}$ to represent latewinter conditions. Using Equation (1), Table 1 shows the resulting amplitude of the surface pressure forcing for four model runs. The summer pressure variations agree with summer field measurements we have made at Summit.

Calculations for these scenarios are run using measured snow and firn permeability profiles from Summit during the summer, and we assume that the permeability profile does not experience large seasonal change. The layering includes regions of high-permeability under lower-permeability horizons that allow for greater airflow velocities in the more permeable buried layers (Albert, 1996). Figure 6a depicts the calculated airflow patterns for $5 \mathrm{~m}$ wavelength, and Figure $6 \mathrm{~b}$ depicts that for a $20 \mathrm{~m}$ wavelength. In each case, the magnitudes of the vectors are scaled to the largest velocity in the case. While the short-wavelength roughness induces airflow down to approximately $2 \mathrm{~m}$, the longer-wavelength surface roughness induces larger relative airflows down to $4 \mathrm{~m}$ in the firn.

In Figure $7 \mathrm{a}$ and b, the laterally averaged interstitial airflow velocities are plotted vs depth for the four conditions above, which bound the expected ventilation patterns at Summit. Because the airflow profile (shown in Fig. 6) is two-dimensional, at any given depth there will be airflow velocities higher and lower than in this plot (due to the location on the sine wave); nevertheless it provides an overall view of the situation. Under high winds, ventilation velocities at the near-surface snow can be up to $3 \mathrm{~cm} \mathrm{~s}^{-1}$ in winter, compared to $1 \mathrm{~cm} \mathrm{~s}^{-1}$ in summer. The frequency of high $12 \mathrm{~m} \mathrm{~s}^{-1}$ winds in summer, however, is less than in winter. Movement of a gas in snow under pure molecular diffusion conditions, in the absence of ventilation, is roughly $0.03 \mathrm{~cm} \mathrm{~s}^{-1}$. Thus, under low-wind conditions, the summer roughness causes ventilation rates that are comparable to diffusion rates, and moderate to high winds would be required for summer ventilation. However, even low-wind conditions acting on the increased snow surface roughness in winter can cause the interstitial airflow (ventilation) to exceed the diffusion rates.
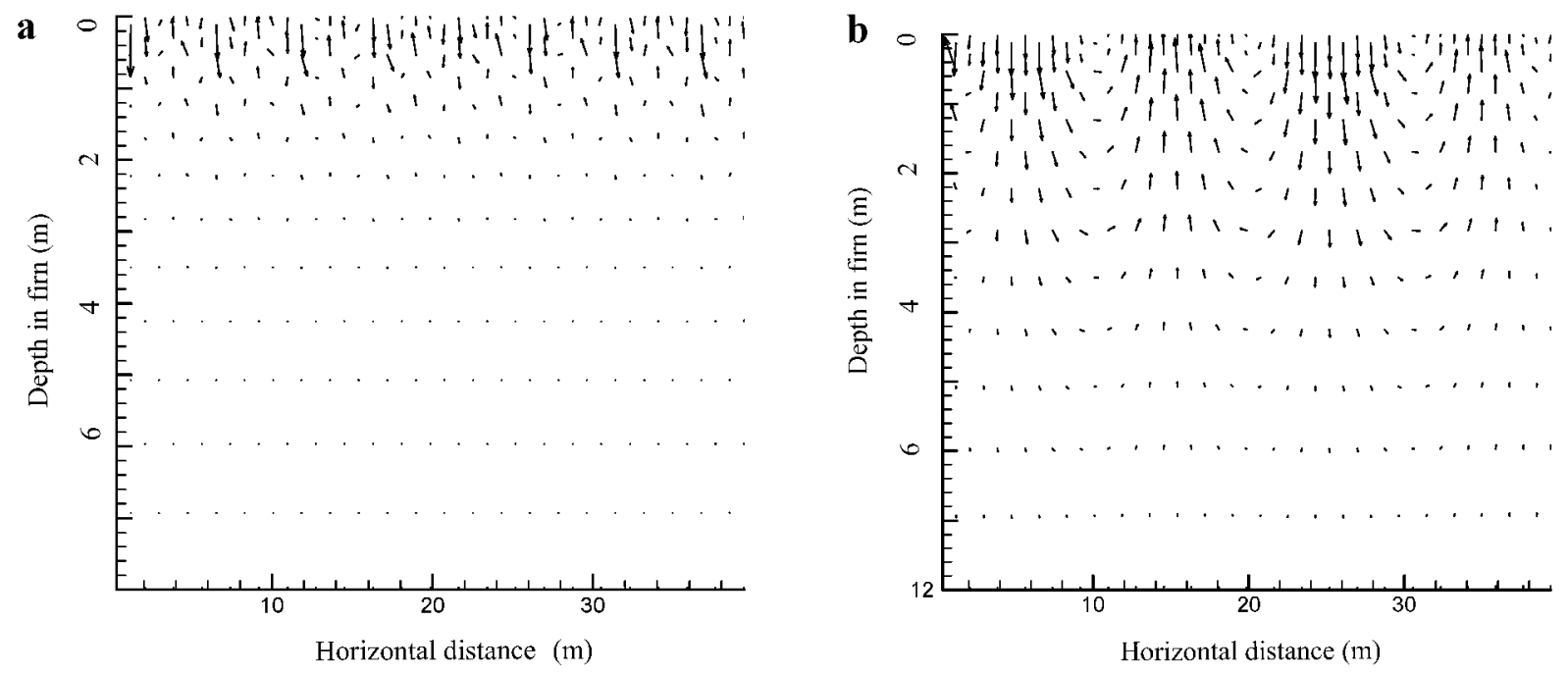

Fig. 6. Calculated airflow patterns in the top $12 \mathrm{~m}$ of firn, when the wavelength of the surface roughness elements is $5 \mathrm{~m}$ (a) and $20 m(b)$. 

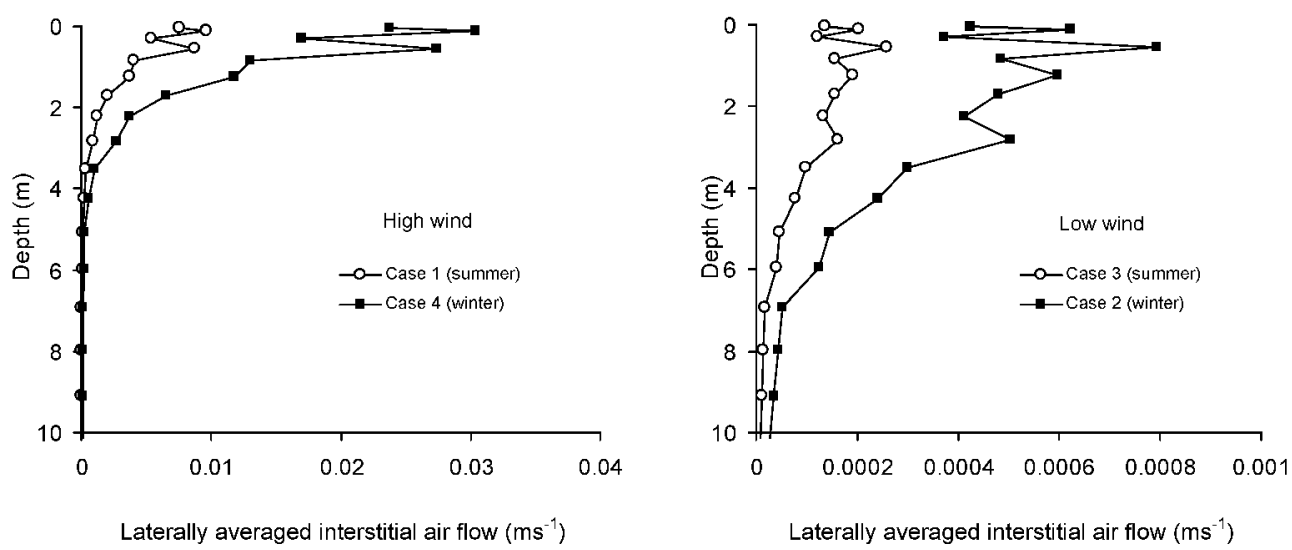

Fig. 7. Laterally averaged airflow magnitudes under low and high roughness amplitudes for short and long roughness wavelengths.

\section{GONGLUSIONS}

Measurements of snow surface roughness at Summit show seasonal differences that can affect ventilation rates. Measured sastrugi amplitudes at Summit were several times larger in February and March than in June-February, apparently due to sustained strong winds and very cold temperatures in winter. Model results assuming a time-invariant permeability profile show that this increase in snow roughness amplitude can cause increased interstitial airflow (ventilation) in winter. Measured snow surface roughness waveleng ths less than about $30 \mathrm{~m}$ show no significant change with season. Under high winds, ventilation velocities at the near-surface snow can be up to $3 \mathrm{~cm} \mathrm{~s}^{-1}$ in winter, compared to $1 \mathrm{~cm} \mathrm{~s}^{-1}$ in summer. The frequency of $12 \mathrm{~m} \mathrm{~s}^{-1}$ winds in summer, however, is less than in winter. Under low-wind conditions, the summer roughness causes ventilation rates that are comparable to diffusion rates. In winter, however, even $5 \mathrm{~m} \mathrm{~s}^{-1}$ winds acting on the higher sastrugi amplitudes can cause the interstitial airflow to exceed the diffusion rates. Seasonally dependent snow surface features exist that can create seasonal differences in advective/diffusive snow-air transfer processes.

\section{AGKNOWLEDGEMENTS}

We thank the winter-over staff for their dedication and hard work under extreme conditions, and we thank several anonymous reviewers for constructive and helpful comments on the manuscript. This work was funded by U.S. National Science Foundation grant NSF-OPP 9530738 and 9813441.

\section{REFERENCES}

Albert, M. R. 1993. Some numerical experiments on firn ventilation with heat transfer. Ann. Glaciol., 18, 161-165.

Albert, M. R. 1996. Modeling heat, mass, and species transport in polar firn. Ann. Glaciol., 23, 138-143.

Benson, C. S. 1971. Stratigraphic studies in the snow at Byrd Station, Antarctica, compared with similar studies in Greenland. In Crary, A. P., ed. Antarctic snow and ice studies II. Washington, DC, American Geophysical Union, 333-353. (Antarctic Research Series 16.)

Colbeck, S.C. 1989. Air movement in snow due to windpumping. F. Glaciol., 35(120), 209-213.

Cunningham, J. and E. D. Wadding ton. 1993. Air flow and dry deposition of non-sea salt sulfate in polar firn: paleoclimatic implications. Atmos. Environ., 27A(17-18), 2943-2956.

Gow, A. J. 1965. On the accumulation and seasonal stratification of snow at the South Pole. 7. Glaciol., 5(40), 467-477.

Gow, A. J. and R. Rowland. 1965. On the relationship of snow accumulation to surface topography at "Byrd Station", Antarctica. F. Glaciol., 5(42), 843-847.

McConnell, J. R., R. C. Bales, R. W. Stewart, A. M. Thompson, M. R. Albert and R. Ramos. 1998. Physically based modeling of atmosphere-to-snow-tofirn transfer of $\mathrm{H}_{2} \mathrm{O}_{2}$ at South Pole. 7. Geophys. Res., 103(D9), 10,561-10,570.

Vanoni, V. A. and L. S. Hwang. 1967. Relation between bed forms and friction streams. ASCE 7. Hydraul. Div., 93(2), 121-144.

Waddington, E. D., J. Cunningham and S. L. Harder. 1996. The effects of snow ventilation on chemical concentrations. In Wolff, E.W. and R.C. Bales, eds. Chemical exchange between the atmosphere and polar snow. Berlin, etc., Springer-Verlag, 403-451. (NATO ASI Series I: Global Environmental Change 43.)

Weller, G. 1969. The heat and mass balance of snow dunes on the central Antarctic Plateau. 7. Glaciol., 8(53), 277-284. 